\title{
Drug Interactions in Patients on Long-term Oral Anticoagulant and Antihypertensive Adrenergic Neuron-blocking Drugs
}

\section{Introduction}

Drug interactions involving oral anticoagulant drugs or adrenergic neuron-blocking antihypertensive agents are well documented (Misage and McDonald, 1970; Mitchell et al., 1970; Robinson and Sylwester, 1970) and are easy to recognize and measure. In hospital close control of therapy is achieved because of the intensive supervision of patients and because accurate information about prescribed drugs is available from drug recording sheets (Crooks et al., 1967).

In general practice the extent of drug interactions is not known. The present studies were carried out on outpatients in the north-east of Scotland on long-term therapy with oral anticoagulants and antihypertensive agents to estimate the extent of potential drug interactions.

\section{Patients and Methods}

Anticoagulant Group.-Two hundred and fifty-four patients (153 men and 101 women) on long-term (more than 6 months) anticoagulant therapy were traced (Table I). They were interviewed at the outpatient anticoagulant clinics over a seven-week period. Information obtained from medical notes, letters, and from the patients' anticoagulant therapy cards was recorded on a standard form. This information was checked with the patient by the same persons (K.J.S. or J.C.P.) and careful inquiry was made about the current intake of drugs either supplied by their practitioner or hospital doctor or taken as self-medication.

\footnotetext{
Department of Therapeutics and Clinical Pharmacology, University of Aberdeen

K. J. STARR, Medical Student

J. C. PETRIE, M.B., M.R.C.P., Senior Lecturer
}

TABLE I-Age and Principal Reason for Long-term Anticoagulant Therapy (254 Patients)

\begin{tabular}{|c|c|c|c|c|c|c|c|c|c|c|}
\hline & \multirow{3}{*}{ Age } & & \multicolumn{4}{|c|}{ Heart Disease } & \multirow{2}{*}{\multicolumn{2}{|c|}{$\begin{array}{l}\text { Peripheral } \\
\text { Vascular } \\
\text { Disease }\end{array}$}} & \multirow{2}{*}{\multicolumn{2}{|c|}{ Other }} \\
\hline & & & \multicolumn{2}{|c|}{ Degenerative } & \multicolumn{2}{|c|}{ Rheumatic } & & & & \\
\hline & & & M. & F. & M. & F. & M. & F. & M. & F. \\
\hline $\begin{array}{c}<30 \\
30-40 \\
40-50 \\
50-60 \\
60-70 \\
70+\end{array}$ & $\begin{array}{l}\because \\
\because \\
\therefore \\
\therefore\end{array}$ & $\begin{array}{l}\because \\
\because \\
\therefore \\
\therefore\end{array}$ & $\begin{array}{r}0 \\
3 \\
38 \\
48 \\
21 \\
2\end{array}$ & $\begin{array}{l}0 \\
1 \\
1 \\
5 \\
5 \\
1\end{array}$ & $\begin{array}{l}0 \\
1 \\
6 \\
8 \\
7 \\
2\end{array}$ & $\begin{array}{r}0 \\
4 \\
18 \\
29 \\
19 \\
1\end{array}$ & $\begin{array}{l}0 \\
0 \\
1 \\
1 \\
6 \\
1\end{array}$ & $\begin{array}{l}1 \\
1 \\
1 \\
3 \\
4 \\
1\end{array}$ & $\begin{array}{l}0 \\
0 \\
1 \\
3 \\
3 \\
1\end{array}$ & $\begin{array}{l}0 \\
1 \\
1 \\
1 \\
2 \\
1\end{array}$ \\
\hline Total & .. & .. & 112 & 13 & 24 & 71 & 9 & 11 & 8 & 6 \\
\hline
\end{tabular}

Possible adverse reactions and the quality of anticoagulant control were recorded. A probable adverse interaction between warfarin and another drug was assessed by variable prothrombin control (more than three times the control value on at least three occasions within the previous 10 visits or six months). The patients were questioned about their awareness of potential hazards of warfarin and phenindione and about altering the pattern of taking other drugs, such as sedatives and analgesics.

Antihypertensive Group.- Sixty-four hypertensive outpatients (34 men and 30 women, age range 38-73 years) on bethanidine, guanethidine, or debrisoquine were traced by the hospital-based drug information system (Coull et al., 1970) and invited to attend for interview. They were questioned about side effects and about their current intake of drugs.

At the end of both surveys the practitioners and hospital doctors were informed of any potential drug interactions.

\section{Results}

\section{ANTICOAGULANT GROUP}

Of the 363 patients in the area on long-term anticoagulant therapy $70 \%$ were interviewed (about one person in 1,000 of the population aged more than 12 years). These included 31 patients (14 men and 17 women) on phenindione. Degenerative heart disease $(73 \%)$ was the commonest principal indication for therapy in men, and rheumatic heart disease $(70 \%)$ was the commonest indication in women.

The patients claimed to be currently taking 741 drugs (men 2.6 ; women 3.4 ) supplied by prescription in addition to those drugs recorded in medical notes, letters, or anticoagulant cards routinely issued to all patients. There was no mention in the medical notes of the 119 drugs being taken as self-medication by $35 \%$ of the men and $43 \%$ of the women. Old drugs and friends' drugs were not taken.

A theoretical potential interaction with warfarin was noted in 85 patients (33\%) with drugs supplied by prescription and in 75 patients $(30 \%)$ with drugs taken as self-medication (Table II). Theoretical potential drug interactions noted in patients on phenindione are not included in the Table because interactions involving phenindione are not well documented. A probable adverse interaction involving warfarin and another drug with loss of anticoagulant control was evident in 22 patients $(9 \%)$. Although drugs taken as self-medication were involved in $47 \%$ of the total potential interactions they were, in fact, being taken by patients in only $9 \%$ of probable adverse interactions. 
TABLE II-Potential Interactions with Warfarin

\begin{tabular}{|c|c|c|c|}
\hline \multirow{2}{*}{ Preparation } & \multicolumn{3}{|c|}{ Potential Interaction } \\
\hline & $\begin{array}{l}\text { Supplied by } \\
\text { Prescription }\end{array}$ & $\begin{array}{l}\text { Self- } \\
\text { medication }\end{array}$ & $\begin{array}{l}\text { Loss of Anti- } \\
\text { coagulant Control }\end{array}$ \\
\hline $\begin{array}{l}\text { Barbiturate . } \\
\text { Dichloralphenazone } \\
\text { Glutethimide } \\
\text { Salicylates } \\
\text { Other analgesic } \\
\text { Clofibrate } \\
\text { Oral hypoglycaemic } \\
\text { Other }\end{array}$ & $\begin{array}{r}33 \\
3 \\
1 \\
2 \\
4 \\
28 \\
7 \\
7\end{array}$ & $\begin{array}{l}\bar{z} \\
\overline{57} \\
\overline{18}\end{array}$ & $\begin{array}{r}11 \\
1 \\
0 \\
4 \\
0 \\
4 \\
0 \\
2\end{array}$ \\
\hline Total & 85 & 75 & 22 \\
\hline
\end{tabular}

Thirty-one patients on phenindione and six patients taking diphenydramine were excluded because of insufficient documentation in man.

Altogether 42 patients (17\%) had substantiated evidence of haemorrhagic episodes at some time since the institution of anticoagulant therapy. Haematuria was the commonest manifestation (Table III). The main sources of information about hazards of therapy are shown in Table IV. Sixty-five per cent. of patients were not adequately aware of the nature and possibility of haemorrhagic complications. Slightly fewer $(52 \%)$ had inadequate knowledge about the hazards of taking additional drugs or of altering their patterns of taking drugs.

TABLE III-Haemorrhagic Complications in Patients on Long-term Anticoagulant Therapy (52 Episodes in 42 Patients)

\begin{tabular}{|c|c|c|c|c|c|c|}
\hline & & & & Men & Women & Total \\
\hline $\begin{array}{l}\text { Haematuria .. } \\
\text { Purpura, ecchymosis } \\
\text { Postmenopausal blee } \\
\text { Severe epistaxis } \\
\text { Eye complications } \\
\text { Haemoptysis } \ldots \\
\text { Melaena } \\
\text { Haematemesis } \\
\text { Other .. }\end{array}$ & $\begin{array}{l}\because \\
\text { ding, me } \\
\because \\
\because \\
\cdots \\
\cdots \\
\cdots\end{array}$ & $\begin{array}{cc}\cdots & \cdots \\
\cdots & \cdots \\
\text { enorrhagia } \\
\cdots & \cdots \\
\cdots & \cdots \\
\cdots & \cdots \\
\cdots & \cdots \\
\cdots & \cdots\end{array}$ & $\begin{array}{l}\cdots \\
\cdots \\
\cdots \\
\cdots \\
\cdots \\
\cdots\end{array}$ & $\begin{array}{l}7 \\
5 \\
2 \\
3 \\
0 \\
2 \\
0 \\
4\end{array}$ & $\begin{array}{l}3 \\
4 \\
6 \\
3 \\
2 \\
4 \\
1 \\
2 \\
4\end{array}$ & $\begin{array}{r}10 \\
9 \\
6 \\
5 \\
5 \\
4 \\
3 \\
2 \\
8\end{array}$ \\
\hline
\end{tabular}

TABLE IV-Main Sources of Information About the Hazards of Anticoagulan Therapy (254 Patients).

\begin{tabular}{|c|c|c|c|}
\hline Source & & $\begin{array}{l}\text { Haemorrhagic } \\
\text { Complications } \\
\text { of Therapy }\end{array}$ & $\begin{array}{l}\text { Drug Hazard } \\
\text { from Interaction } \\
\text { or Altered Dosage }\end{array}$ \\
\hline $\begin{array}{l}\text { Information adequate } \\
\text { Hospital doctor } \\
\text { General practitioner } \\
\text { Other... } \\
\text { Information inadequate }\end{array}$ & $\begin{array}{ll}. & \\
\because & \cdots \\
\because & \cdots\end{array}$ & $\begin{array}{c}67 \\
9 \\
14 \\
164(65 \%)\end{array}$ & $\begin{array}{c}67 \\
31 \\
23 \\
133(52 \%)\end{array}$ \\
\hline
\end{tabular}

\section{ANTIHYPERTENSIVE GROUP}

Nasal congestion or asthma or depression were noted in 26 patients $(41 \%)$. Theoretical potential interactions with either sympathomimetic or antidepressant drugs were present in 22 patients $(34 \%)$ (Table V). Probable adverse interactions were

TABLE v-Potential Interactions with Antihypertensive Agents

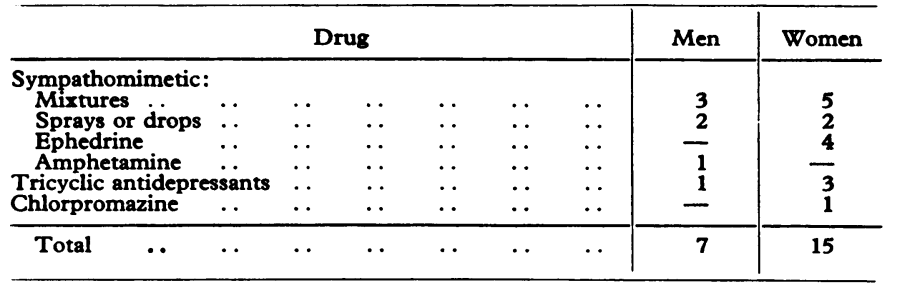

noted at the time of the interview in one patient on imipramine and in two patients who were on ephedrine. A severe loss of hypotensive effect was evident and recorded (diastolic blood pressure $>130 \mathrm{~mm} \mathrm{Hg}$ ).

\section{Discussion}

The study of the frequency of the occurrence of drug interactions in the community is of clinical importance because patients are not under close day-to-day supervision. The extent of drug interaction is difficult to estimate because interactions cannot be recognized by the patient or doctor unless either is aware that they may occur. In addition, in general practice, where $90 \%$ of prescriptions are issued (Lancet, 1971), the facilities for recording and transferring information about drug therapy are not satisfactory (Beveridge and Petrie, 1972). Large-scale retrospective studies depending on practice records are not at present possible.

The North-east of Scotland Region has built-in advantages for estimating the extent of the occurrence of interactions because the Hospital Group serves the entire community (Petrie et al., 1972) and the patients seen at the clinics are representative of the medical care of the population of the region. There is no reason to believe that the situation concerning drug interactions is different in other parts of the country. The anticoagulant and antihypertensive drugs are particularly suitable for study because the supervision of the long-term therapy of patients occurs at the interface between general practice and hospital. Access to the clinical records and to the patients is therefore possible, although the patients remain based in the community.

Interactions involving oral anticoagulant drugs or antihypertensive agents have been well publicized but the number of prescriptions issued in general practice is not large. J. Berkeley (personal communication, 1972) in a representative sample of practitioners who participated in the North-east of Scotland general practice Work Load Study has shown that a prescription for warfarin or adrenergic neuron-blockers was written in $0.25 \%$ and $1 \%$ respectively of all consultations at which a prescription was issued. In the patients on long-term anticoagulant therapy a theoretical potential adverse drug interaction was noted in onethird of the patients with drugs issued by prescription and in a similar number with drugs taken as self-medication. Nevertheless, a probable adverse interaction with warfarin as judged by several unstable prothrombin times was noted at the time of the interview in only $9 \%$ of patients, although many interactions may not have been detected because patients on anticoagulant therapy are usually seen for outpatient review of therapy only every fourth to eighth week. Probable adverse drug interactions were more often associated with drugs issued by prescription than with drugs taken as self-medication. The explanation is that many patients take drugs as self-medication but large doses of salicylates are required significantly to alter anticoagulant control (Udall, 1969).

The estimate of the occurrence of haemorrhagic episodes is unreliable, as these episodes were recorded in retrospect from notes and could therefore not confidently be solely attributed to probable adverse drug interaction. The apparent lack of awareness by the patients of the hazards of anticoagulant therapy, of the hazards of altering the patterns of drug taking, or of the need to carry the anticoagulant card, was clear. In these patients the transfer of information about current drug therapy supplied by prescription or about drugs taken as self-medication was unsatisfactory as was also noted in a study of patients referred to medical units (Beveridge and Petrie, 1972).

In patients on adrenergic neuron-blocking drugs, such as guanethidine, bethanidine, or debrisoquine, either decongestants containing sympathomimetic amines, such as phenylephrine, phenylpropranolamine, and ephedrine, or tricyclic antidepressants, such as imipramine and amitriptyline, contribute to a loss of control of blood pressure (Aminu et al., 1970; Misage and McDonald, 1970; Mitchell et al., 1970). Nasal congestion and depression are both recognized side effects of adrenergic neuronblocking drugs, and it is not surprising that one-third of the patients interviewed were at risk to a theoretical potential drug interaction, particularly to sympathomimetic amines which are widely available as constituents of combined preparations either "over the counter" or issued by prescription. A probable adverse 
drug interaction was noted at the time of the interview in only three patients but as they were seen on only one occasion many more may have had varying blood pressure levels.

These studies show that in patients in the community on long-term anticoagulant or antihypertensive drugs particular care is required when additional drug therapy is prescribed and when the patient is advised about self-medication. A record of current drug therapy must be maintained and be available to allow the rational prescription of additional drugs and the review of all drug therapy at each patient-doctor contact. Further studies of other well-recognized drug interactions are required in the community to indicate the relevance and clinical importance to doctors who prescribe drugs of the formidable lists of substances which interact, such as the 410 pages of tables recently compiled by Martin (1971). Possibly the inappropriate prescription of fixed doses of a drug to patients in whom wide differences in the absorption, distribution, metabolism, and excretion of the drug may occur may be as important, if not more so, than drug interactions.
We thank Dr. D. C. Coull, Dr. A. A. Dawson, Mr. W. H. Carnie, and the general practitioners and consultant physicians of the area for their help with these studies.

\section{References}

Aminu, J., D'Mello, A., and Vere, D. W. (1970). Lancet, 2, 935

Beveridge, T., and Petrie, J. C. (1972). British Medical fournal, 2, 37. Coull, D. C., Crooks, J., Davidson, J. F., Gallon, S. C., and Weir, R. D. (1970). European fournal of Clinical Pharmacology, 13, 46.

Crooks, J., Calder, G., and Weir, R. D. (1967). Fournal of the Royal College of Physicians of London, 1, 233.

Lancet, 1971, 1, 1227.

Martin, E. W. (1971). In Hazards of Medication. Philadelphia, Lippincott.

Misage, J. R., and McDonald, R. H. (1970). British Medical fournal, 4, 347. Mitchell, J. R., Cavanaugh, J. H., Arias, A., and Oates, J. A. (1970). fournal of Clinical Investigation, 49, 1596

Petrie, J. C., Needham, C. D., and Gillanders, L. A. (1972). British Medical fournal, $2,78$.

Robinson, D.' S., and Sylwester, D. (1970). Annals of Internal Medicine, 72,

Sigell, L. T., and Flessa, H. C. (1970). Fournal of the American Medical Association, 214, 2035.

Udall, J. A. (1969). American fournal of Cardiology, 23, 104.

\title{
Effect of Heparin on Renal Function in Patients With Oliguria
}

\author{
E. N. WARDLE, P. R. ULDALL
}

British Medical fournal, 1972, 4, 135-138

\section{Summary}

The effect of short-term administration of heparin has been studied in seven patients with oliguric glomerulonephritis, five with accelerated hypertension, and three with transplant rejection. Measurements were made of the glomerular filtration rate, radiofibrinogen catabolism, and complement inhibition. Beneficial efiects on fibrinogen catabolism were found in some cases of accelerated hypertension and transplant rejection, but heparin alone had no dramatic effect in glomerulonephritis. Heparin produced an increase of glomerular filtration rate, but in-vivo inhibition of complement by heparin was small.

\section{Introduction}

Platelet and fibrin deposits are found in the renal glomeruli of patients with rapidly progressive glomerulonephritis, malignant hypertension, and transplant rejection when such patients have oliguria. Persistence of fibrin may account in part for reduction of glomerular filtration. In the case of glomerulonephritis circulating immune complexes, when concentrated in the renal filters, damage platelets (Cochrane and Dixon, 1968) so that intraglomerular coagulation follows. The natural renal protective mechanisms are its endothelial cell fibrinolytic potential (Holemans et al., 1965; Holemans et al., 1967), resulting in the production of small fibrin degradation products which themselves protect platelets from aggregation (Larrieu et al., 1967) and immune damage (Salmon and Lambert, 1971), and the phagocytic capacity for fibrin and immune complexes of the mesangial and endothelial cells (Vassalli and McCluskey, 1965).

Department of Medicine, Royal Victoria Infirmary, Newcastle upon Tyne

E. N. WARDLE, M.B., M.R.C.P., Senior Registrar

P. R. ULDALL, M.D., M.R.C.P., Consultant Nephrologist
Similar platelet deposition and coagulation is a feature of certain types of transplant rejection (Porter, 1967; Burrows et al., 1970). In malignant hypertension it is likely that the high intravascular tension, leading to fibrin insudation through arteriolar walls, also damages endothelial cells (Wardle, 1971), which even in arteries do have some fibrinolytic activity (Onoyama and Tanaka, 1969). Platelet adhesion may follow, possibly because of exposure to subendothelial collagen and acid mucopolysaccharides (Murase et al., 1971). Indeed, the proliferative response that is seen in the glomeruli in malignant hypertension is probably due exclusively to fibrin deposition (Ben-Ishay, 1967).

Kincaid-Smith et al. (1968) reported that heparin given as part of a regimen that included corticosteroids and immunosuppressive drugs greatly improved the urine output of six cases of "irreversible" acute renal failure due to glomerulonephritis. Such a measure is a logical extension of the use of heparin in experimental nephritis to prevent glomerular sclerosis (Silfverskiold, 1940; Kleinerman, 1954). Other groups have likewise reported the favourable effects of heparin on the course of glomerulonephritis (Shires et al., 1966; Conte et al., 1970; Cade et al., 1971) and transplant rejection (McMillan, 1968; MacDonald et al., 1970). The bad prognosis of anuric glomerulonephritis is well known (Merrill, 1957). Heparin has great potential in theory because it is not only the only effective antithrombin but it has also anti-inflammatory and anticomplementary actions (Ecker and Gross, 1929). Caution in the interpretation of results is necessary because heparin has a diuretic action (Majoor et al., 1960) due to antagonism of the renin-angiotensin-aldosterone system (Schlatmann et al., 1964). Moreover, control of heparin therapy can present special difficulties in the uraemic patient (Pitney et al., 1970), in whom there is not only hypercoagulability and heparin resistance but also a metabolic platelet defect.

We report here the results of a study of the effect of heparin on renal function in 15 patients with oliguria or declining renal function due to glomerulonephritis, malignant hypertension, or transplant rejection which was monitored by measurement of the true glomerular filtration rate, by serial estimation of ${ }^{51} \mathrm{Cr}$ edetic acid clearance, and by studies of radiofibrinogen cata- 